\title{
The Decision Support System BodenseeOnline for Hydrodynamics and Water Quality in Lake Constance
}

\author{
Ulrich Lang ${ }^{1}$, Roland Schick ${ }^{2}$ and Gerd Schröder ${ }^{3}$ \\ ${ }^{1}$ Engineering Consultant Prof. Kobus and Associates, Wilhelmstr.11, 70182 Stuttgart \\ ${ }^{2}$ Zweckverband Bodensee-Wasserversorgung, Süßenmühle 1, D-78354 Sipplingen \\ ${ }^{3}$ Institute for Lake Research of LUBW, Argenweg 50/1, 88085 Langenargen
}

Germany

\section{Introduction}

Lake Constance is a large prealpine lake. It is an unregulated natural body of water which is of very high cultural and ecological value, a unique tourist attraction, and an important drinking water resource. The Lake is an international water body, located between Germany, Switzerland, and Austria (Fig.1). It drains a total catchment area of $11000 \mathrm{~km}^{2}$ with an average annual total discharge of $12 \mathrm{~km}^{3} / \mathrm{a}$ from a considerable number of tributaries, of which the Alpenrhein provides about $60 \%$. The lake has a total volume of 48 $\mathrm{km}^{3}$ and consists of two parts: the upper basin with a surface area of about $473 \mathrm{~km}^{2}$, extending over a length of more than $60 \mathrm{~km}$, and the lower basin with about $63 \mathrm{~km}^{2}$, which is located downstream and connected by a short river reach (Seerhein) in Konstanz. The upper basin has an average depth of $90 \mathrm{~m}$, with a maximum depth of $254 \mathrm{~m}$ and several extended shallow areas along the shoreline.

The Bodensee region was settled in prehistoric times and since then has played a prominent role in European history. In the last century, the area has experienced a fast economic growth, industry developments, and considerable population growth. At the same time, the natural lake at the rim of the Alps has become a unique tourist attraction. These developments have led to increasingly negative effects upon the lake water quality, which have triggered a combined effort of the riparian states. In 1959, the "Internationale Gewässerschutzkommission Bodensee (IGKB)" (International water protection commission for Lake Constance) was formed, and the riparian states have taken consequential steps for reducing the waste water inputs into the lake. Within several decades, these efforts have lead to a continuous improvement of the lake water quality, which by now has reached nearly its natural quality again, which meets drinking water standards.

\subsection{Motivation}

Lake Constance is the most important natural resource of drinking water in the southwest of Germany and in the Lake Constance region of Switzerland. Drinking water is abstracted in 16 locations around the lake (see Figure 1). More than five million people are supplied with drinking water from Lake Constance. The main water supplier of Lake Constance is the

Source: Decision Support Systems, Advances in, Book edited by: Ger Devlin, ISBN 978-953-307-069-8, pp. 342, March 2010, INTECH, Croatia, downloaded from SCIYO.COM 
Bodensee-Wasserversorgung (BWV). The BWV delivers drinking water into the region of Stuttgart, the capital of Baden-Württemberg. Half the population of Stuttgart obtains the drinking water from Lake Constance. The average delivery of drinking water is $4 \mathrm{~m}^{3} / \mathrm{s}$.

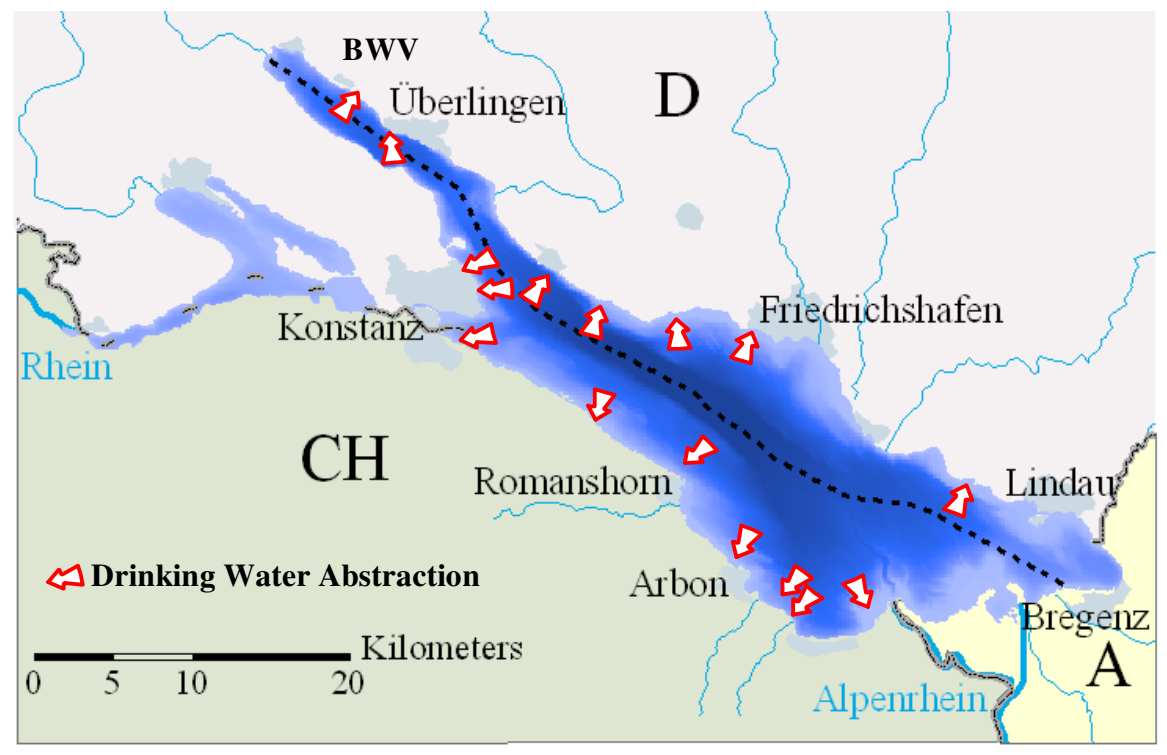

Fig. 1. Map of Lake Constance with drinking water abstractions

Lake Constance is under large pressure due to the intensive tourism and increase in population with an enlargement of industrial areas in the watershed and intensive agricultural uses as well. The main sources of hazards and risks for the water quality are accidents by transportation on the railways and roads around the lake and the air traffic to and from Zürich Kloten. Two terrible accidents with airplanes in the Lake Constance region demonstrate the vulnerability of the important drinking water resource. In 1994 a small aircraft fell into the lake near one of the main drinking water abstractions. It was supposed that nuclear material had been on board and the safety of the drinking water was questioned. In 2002 two airplanes crashed near Überlingen and it was incredibly lucky that the lake was neither affected nor partially contaminated by aircraft debris. The intensive use of Lake Constance by navigation and sailors is an additional source of hazards and risks for the water quality and the ecological system of Lake Constance. Initiated from the open questions around the two airplane crashes and based upon the potential risk of contaminations by hazardous material a decision support system for accident precaution is required for the lake.

Additionally, impacts due to extreme weather or hydrological conditions can affect the lake system temporarily. Extreme wind events or strong rainfall with flood conditions in the tributaries (e.g. August 2005) or high water levels in Lake Constance (Summer 1999) are examples that affect the lake temporarily. The flood event in August 2005 caused a high sediment inflow to the lake with resulting turbidity over more than half a year in the whole lake. Also, problems with driftwood occurred on the northern shore. 
High water levels, such as in summer 1999, have tremendous impacts upon the shore. Buildings have to be protected and ecological damage on the reed areas are the consequences of high water levels in Lake Constance.

\subsection{Objectives}

A decision support system for Lake Constance has been developed in a multidisciplinary research project over a period of three years. This research project was financed by the German Research Foundation (Deutsche Forschungsgemeinschaft) and the Federal Ministry of Education and Research (Bundesministerium für Bildung und Forschung). The objective of the research project "BodenseeOnline, an Information System for Hydrodynamics and Water Quality" was to collect all relevant data and information for decision support, to develop numerical models for the prediction of hydrodynamic and water quality processes in the lake and to distribute the information to the stake holders. The decision support system BodenseeOnline has to deliver online or real time information about the up to date status of the lake. Three- dimensional numerical models calculate the interpretation of the lake status. These models must include all relevant processes affecting the lake hydrodynamics and major ecological components. The models calculate the transport of substances and simulate the nutrient cycle. They have to be validated with measured information and tested for a robust application in a continuous online model.

\section{Hydrodynamic and ecological processes of Lake Constance}

\subsection{Hydrodynamics}

The major driving forces of the flow and transport processes in the lake are shown in Fig.2. The energy transfer from the atmosphere leads to the typical seasonal heating of the water surface in spring and cooling in autumn, which in turn triggers the typical summer stratification and the turnover with complete mixing during winter.

Lake Constance is a monomictic lake with a stratification period between spring and late autumn. The surface temperature reaches values up to $20^{\circ} \mathrm{C}$ in summertime. The epilimnion thickness increases during the stratification period up to 20-30 m. The hypolimnion water temperature varies between 4 and $5^{\circ} \mathrm{C}$. The deep water is exchanged periodically after cold winters. The exchange of deep water takes place every 4 to 5 years dependent on the number of frost days, which are defined as days with air temperature below $0^{\circ} \mathrm{C}$.

The major driving force of the lakewide circulation is the wind, which shows a highly variable distribution over the lake due to the local topography (Alps). The wind forces cause a complex flow field with internal waves in the stratified case. The Kelvin wave which travels counter clockwise around the lake has a period of $4-5$ days depending on the stratification (thickness of epilimnion and temperature difference between epilimnion and hypolimnion). Due to the dimensions of the lake, these large-scale motions are modified by the Coriolis force.

The inflow and outflow conditions and all inputs of substances from tributaries or waste water treatment plants have to be considered to determine boundary conditions for the water quality and the transport characteristics of the lake. The main tributary is the river Alpenrhein, which flows into the eastern part of the lake. Because of the large load of suspended solids, dams have been built to lead the river plume with sediments to the deepest part of the lake. During flood events, density driven underflows with high sediment load can occur and can be observed mainly in the eastern part of the lake. 
The lake geometry shows a number of specific features, in particular the "sill of Mainau", which separates the main upper Lake from the Überlinger See. Typical for prealpine lakes, the major inflow with floods and high water levels occurs during the snowmelt (late spring). In late summer to the winter season, often low flow situations are encountered.

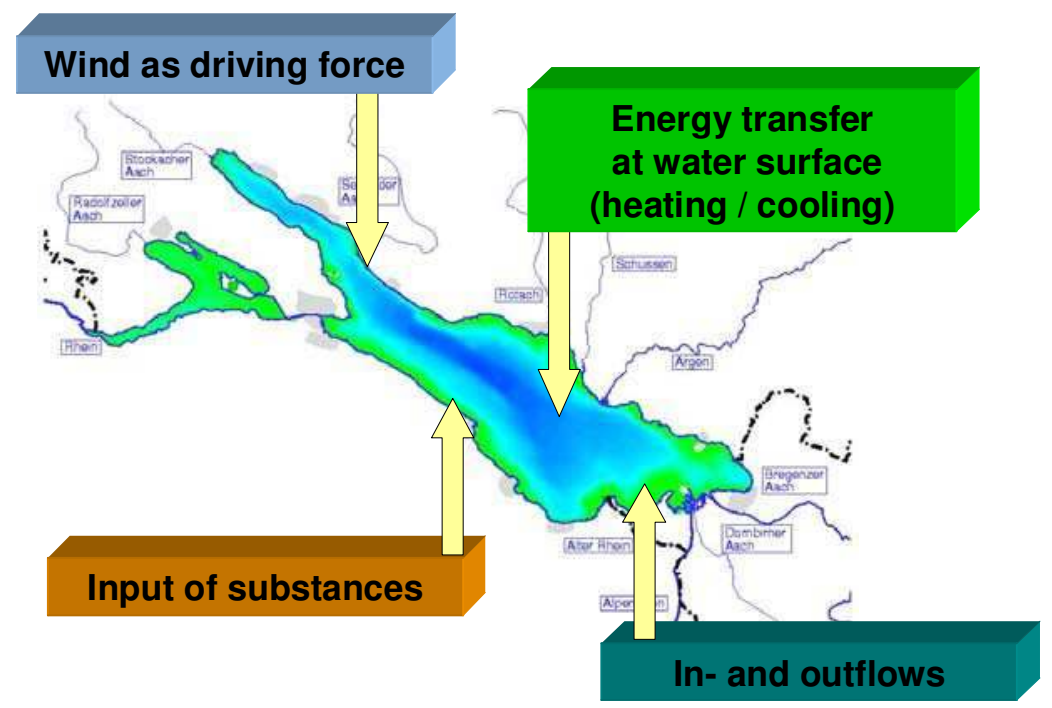

Fig. 2. Driving Forces and Inputs

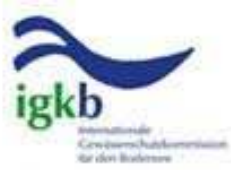

\section{Total Phosphorous in Lake Constance}

$$
\mathrm{mg} / \mathrm{m}^{3} \quad 1951-2005
$$

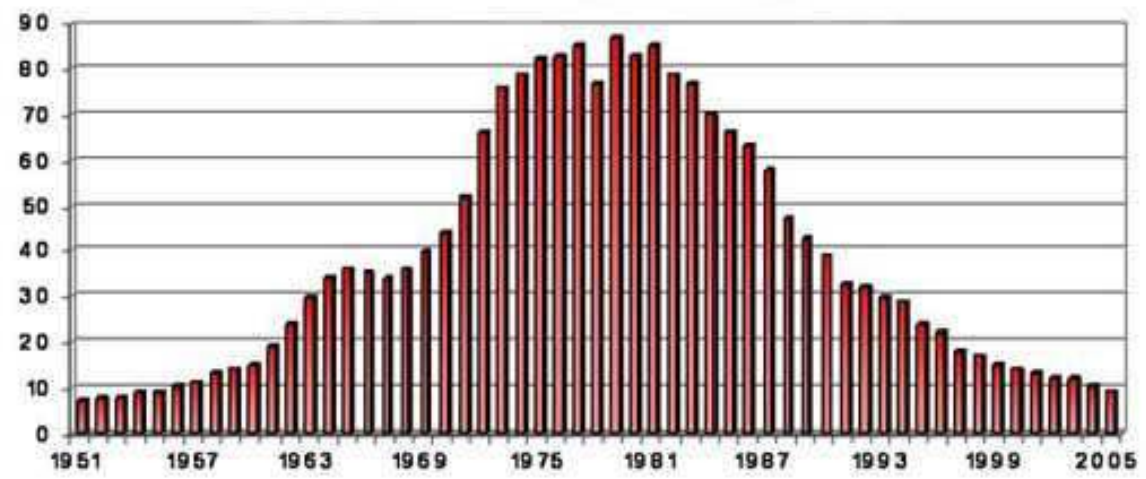

Fig. 3. Development of phosphorous concentrations between 1950 an 2005 (IGKB, 2004) 


\subsection{Ecological long term impacts}

Before the industrialisation started after the Second World War, Lake Constance was an oligotrophic lake with low phosphorous concentrations, the limiting factor of the nutrient cycle. The lake became eutrophic during the sixties and seventies of the last century due to a high nutrient load from the tributaries and waste water (see Figure 3). The phosphorous concentrations reached levels of more than $80 \mathrm{mgP} / \mathrm{m}^{3}$ around 1980. This led to large algae plumes during the summer period, which reduced the attractiveness of the lake for tourists. The bad water quality due to the algae plumes at the lake surface wasn't the only pollution risk for the lake. The large eutrophication threatened the deeper parts of the lake to become oxygen free. Several strong winters with cold air temperatures preserved the lake from an anaerobic hypolimnium before the efforts of enhanced waste water treatments have been effective. The phosphorous concentrations have now reached values of less than $10 \mathrm{mg} / \mathrm{m}^{3}$, (as P) which were observed before the eutrophication started. The result is now a good water quality for the lake with rare algae plumes in summer which has to be preserved for the future.

\section{BodenseeOnline model concept and database}

A research team of five partner institutions has developed an Online Information System, which allows numerical simulation of the three-dimensional flow and transport processes of dissolved substances and sediments as well as the major biogeochemical cycle in Lake Constance. The components of the system "BodenseeOnline" are shown in Fig.4. The dynamic flow pattern in the lake can be simulated adequately and with high time resolution by coupling the wind model MassConsitentFlowmodel (MCF Scheuermann et al., 2008) for the regional wind distribution with the hydrodynamic model ELCOM (Hodges \& Dallimore 2006). The coupled hydrodynamic-ecological model ELCOM-CAEDYM (Hipsey et al., 2007) is used to simulate the three-dimensional ecological processes in the lake.

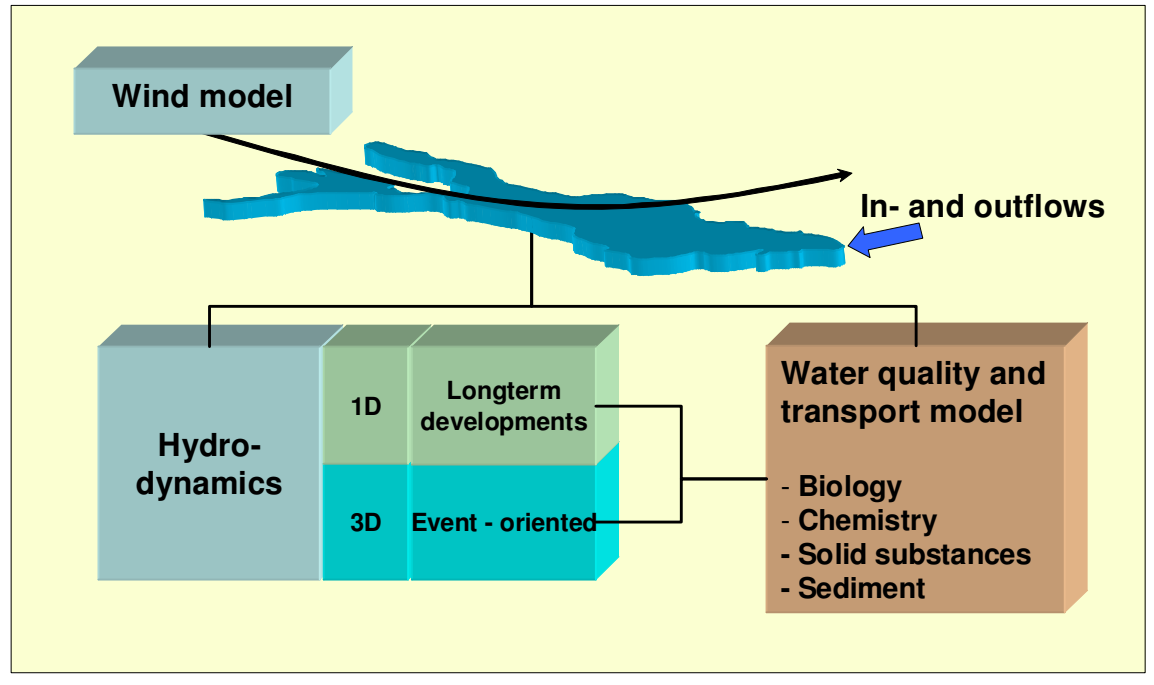

Fig. 4. The model system 
For long-term considerations, the one dimensional model DYRESM (Hamilton \& Schladow 1997) has been successfully applied in combination with the water quality model Computational Aquatic Ecosystem Dynamic Model (CAEDYM) (Hipsey et al., 2007) for the simulation of algal growth in spring, as well as for long-term shifts in the algal community composition attributable to the ongoing reoligotrophication of the lake.

The surface wave model Simulating WAves Nearshore (SWAN, Holthuijsen et al., 1989) is applied to estimate the two-dimensional wave structures on the lake surface introduced by wind. The framework of BodenseeOnline is shown in Fig.5. The hydrological data for the entire catchment and all tributaries, as well as, all data taken by the state water authorities around the lake are provided daily by the three riparian countries. The national weather services provide the meteorological data and forecasts, and all water suppliers provide the data taken at their intake structures. The data is stored in the database, to which all users have access. The data base is split into two main parts: the data base of the measurements and the simulation results. Both parts can be visualized via a web interface. The access is restricted by user login with individualized views of the data.

In the decision support system BodenseeOnline, the various model components are directly linked to the BodenseeOnline database. The models are interactive: Estuary, Lake, and Coastal Ocean Model (ELCOM) for the flow and transport in the lake, MCF for the wind field above the lake as the dominant driving force for the flow and the internal waves, and CAEDYM for modelling the water quality. In order to provide the actual dynamic state of the lake, the model system contains a quarterly period of the lake dynamics, which is updated daily. This provides direct information about the actual dynamic state of the lake and a three day forecast of the lake dynamics. The actual predictions provide a unique prewarning system in case of accidents or extreme events.

\section{Measurements of driving forces}

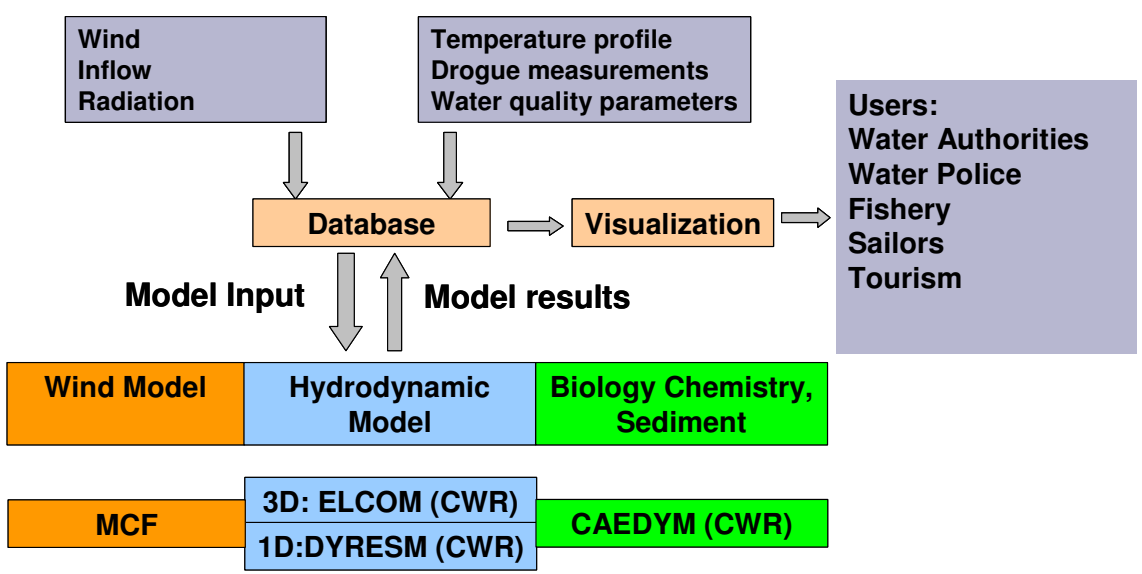

Fig. 5. Framework of the decision support system BodenseeOnline

\subsection{Wind model}

The wind model MCF covers an area of $70 \times 40 \mathrm{~km}$ around the lake. The three-dimensional wind model simulates the wind distribution in the planetary boundary layer, which can be 
divided into the laminar boundary layer near ground surface, the Prandtl layer, and the Eckman layer as the boundary to the geostrophic wind. The orography defines the lower boundary, which includes the roughness of the surface with small roughness coefficients on the lake. The MCF model is a diagnostic, mass consistent, and free of divergence wind field which calculates hourly a steady state distribution of the wind. The model is driven by locally measured wind information or simulation results of a global wind model from the German weather survey which delivers the wind prognosis over the next three days.

\subsection{Hydrodynamic model}

The hydrodynamic lake ELCOM model is based on a finite difference approach. The numerical mesh consists of 52 layers in the vertical with a layer thickness of $2.5 \mathrm{~m}$ in the upper and $10 \mathrm{~m}$ in the lower part. The horizontal grid has a basic grid size of $400 \mathrm{~m}$ respectively, and $100 \mathrm{~m}$ at the river inflows and in the shallow areas.

The hydrodynamic model simulates the surface thermodynamic processes and mass fluxes at the lake surface. The surface exchanges include heating due to short wave radiation penetration into the lake and the fluxes at the surface due to evaporation, sensible heat (i.e. convection of heat from the water surface to the atmosphere) and long wave radiation. The short wave radiation is a direct input to the model from measurements. The incident long wave radiation (ILWR) is calculated by Iziomon et al. (2003) with data for vapour pressure e, air temperature $\mathrm{T}$ and cloud cover $\mathrm{N}$.

$$
I L W R=\sigma \cdot T^{4}\left[1-X_{S} \cdot \exp \left(\frac{-Y_{S} \cdot e}{T_{a}}\right)\right] \cdot\left(1+Z_{S} \cdot N^{2}\right)
$$

Based on measurements from the black forest, the parameters $\mathrm{Xs}_{\mathrm{s}}=0.35, \mathrm{Ys}=10$ and $\mathrm{Zs}=$ 0.0035 have been calibrated.

The heat energy budget of the lake implies a variable density of the lake water dependent upon the water temperature. Additionally, the density of the lake water varies due to salinity and load of suspended solids. The suspended solids are introduced by the river inflows. The major solid load takes place during flood events of the main rivers (e.g. Alpenrhein). The density of the Alpenrhein water increases significantly in cases of flooding. The sediment concentration of the Alpenrhein is only weekly measured. Thus continuous information of the sediment concentration is not available and must be deduced from the long term measurement relationship between discharge $Q$ and sediment concentration $\mathrm{C}_{\mathrm{s}}$ as:

$$
C_{S}=0,0004 \cdot Q^{2,2069}
$$

The hydrodynamic online model simulates the development of the water temperature, salinity and sediment concentration. The river plumes are marked with a conservative tracer to determine the spatial distribution of the river water in case of accidents in the catchments.

\subsection{Ecological model}

An ecological model was integrated in the online model system BodenseeOnline running on Lake Constance simulating plankton succession and nutrient dynamics of this large lake. The ecological model (CAEDYM) is coupled with a hydrodynamic model. Input data for this 
coupled hydrodynamic-ecological model system are meteorological variables and time-series for inflow volume and nutrient loads of the inflowing rivers stored in the common data base. The core of the ecological model consists of a classical nutrient-phytoplankton-zooplankton (NPZ-) model, including the associated dynamics of phosphorus, nitrogen, and silica. For a proper representation of phytoplankton succession, four functional phytoplankton groups with specific physiological properties have been defined. By analysing the occurrences of these four functional groups in the field, distinguishable succession patterns emerged and model simulations were able to reproduce these patterns found within the observations.

The parameter set of the ecological model was defined by calibrating a three year period of phytoplankton development. The ecological model was coupled with the one-dimensional hydrodynamic model DYRESM to simulate the vertical mixing and thermal stratification dynamics of the lake.

For the online simulation, the ecological model has been coupled with the three-dimensional hydrodynamic model ELCOM on a regular coarse grid of $400 \mathrm{~m}$ cell size allowing spatially explicit simulations of the ecosystem.

\subsection{Surface wave model}

The wave model SWAN is used to simulate the spatial pattern of surface waves of the lake. The input for the wave model is the bathymetry and the two-dimensional wind field calculated by the wind model. The wind model provides information on the wave height, length, and period. The model runs in a predictive mode and delivers the users (e.g. sailors and navigation) of BodenseeOnline the expected wave data for the next three days.

\subsection{Web based visualization}

The user interface of BodenseeOnline is web-based access to the information. General information about the actual wind conditions, the flow field at the lake surface, the water temperatures, and the waves are available to the public. This data is presented in a map similar to the weather forecast. This map is updated daily and hourly, information for the next three days is presented. Further information needs a password to protect user access. The specific users have the possibility to select time series of measured data stored in the database. The data can be displayed in graphs or downloaded for individual analysis. The update interval of the measurements is between 10 minutes and once the day depending upon the type of data and data owner.

The simulation results are stored in the database and can be visualized by the user in three different ways:

\section{Vertical profiles:}

The calculated parameters (e.g. temperature, algae concentration or concentration of river water) can be visualized at one location over depth (y-axis) in time (x-axis). Fig. 6 shows the concentration of calculated chlorophyll $\mathrm{A}$ and zooplankton concentration in the spring and summer of 2009. The algae started to grow in April after a stable stratification developed in Lake Constance. The maximum algae plumes were calculated to be in May before the zooplankton starts to proliferate.

\section{Vertical cross sections:}

All parameters can be visualized in given vertical profiles along the length axis of lake and perpendicular to the length axis. Because of the transient simulation, the time dependent development of the parameters can be presented in movies for individual time periods. 


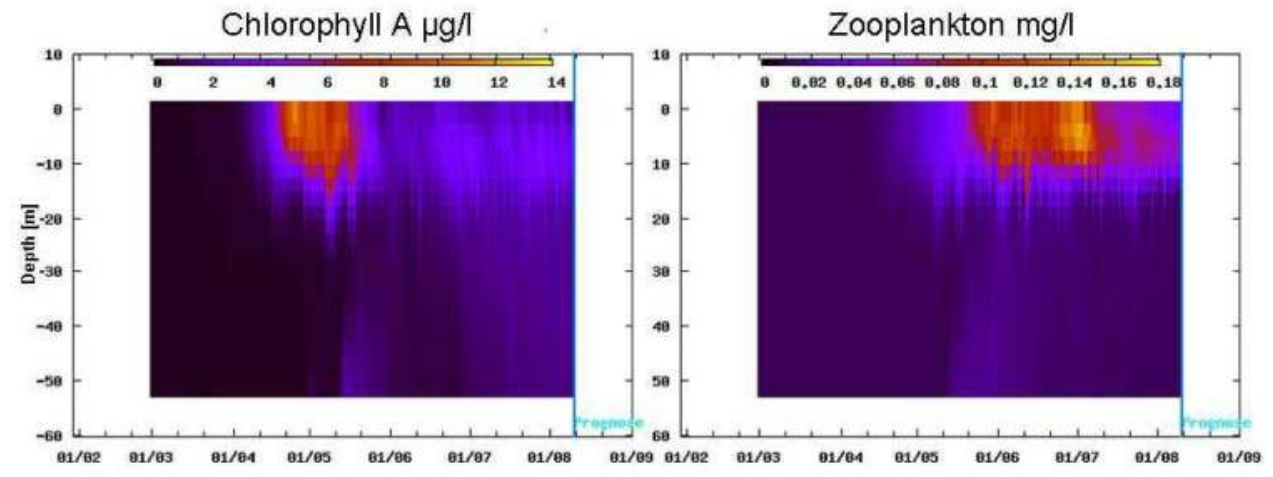

Fig. 6. Calculated profiles of chlorophyll A concentration and zooplankton concentration in BodenseeOnline in spring 2009

\section{Horizontal cross sections:}

The visualization of horizontal cross section is realized by using the Geographical Information System "GISTerm web" developed by the company disy. The GIS allows the selection of individual time steps at different vertical depths. The system reads the data from the database and prepares a shape-file for the selected parameter. This shape-file can be combined with topographic information and further simulation results.

One important feature of BodenseeOnline is the calculation of user-defined pathways in the calculated transient flow field. The flow path calculation is possible with the following options for several practical applications:

- Simulation of a single or multi particle movement: What is the expected arrival area of contaminants transported from a single release point?

- Simulation in the flow direction: Where does a contaminant move?

- Simulation against the flow direction: Where does a contaminant come from?

- Simulation of drift wood on the lake surface: Additionally to the lake current the drift by wind can be included in the flow path calculation by specifying the drag coefficients of a float

An example of calculated particle tracking movements in different depths of the lake is shown in Fig. 7. During the same time period particles can move in totally different directions from a common release point when these particles are placed in different depths.

\section{Validation of the model system}

The BodenseeOnline system provides an up-to-date overview of the present dynamic state of the lake and predictions for the short-term ( 3 days) developments of flow and water quality, based upon the meteorological forecasts. The prototype of BodenseeOnline has been validated for a variety of cases with measured data. The major validations are:

- Measurement campaign 2001 to evaluate the internal wave modelling

- Flood event August 2005 to evaluate the density driven inflow of suspended solids with lakewide transport

- Measurement campaign 2007 to evaluate the three-dimensional ecological modelling 


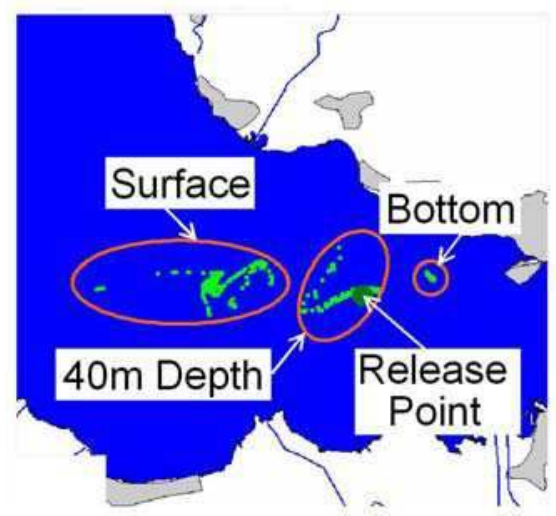

Fig. 7. The three-dimensional flow field: calculated simultaneous particle transport at various depths from a common release point

The validated BodenseeOnline system provides a suitable decision support tool for questions related to precautionary water resources protection, drinking water supply, and water resources management.

\subsection{Measurement campaign 2001}

In the model validation, a first field campaign has been conducted in 2001 (Appt and Stumpp, 2002). Nine thermistor chains have been installed in the lake to measure the temporal development of the vertical temperature profiles with the local internal wave structure (Appt et al., 2004). Each observation location has been additionally equipped with a wind sensor to observe the two-dimensional wind fields over the lake.

The lake was still stratified at the beginning of the field campaign. The epilimnion had a thickness of nearly $25 \mathrm{~m}$. The meteorological conditions during the field campaign in autumn 2001 can be divided in two phases. The first phase was dominated by weak wind which introduced the typical Kelvin wave travelling counter clockwise in a three to four day period around the lake. A strong wind event started in the second period on $8^{\text {th }}$ of November 2001. The wind came from a southwesterly direction with a maximum wind speed of $12 \mathrm{~m} / \mathrm{s}$. The duration of the wind event was nearly three days.

In Fig.8 it shows a longitudinal section through the lake, where the wind forces the surface water to move eastwards and in consequence leads to a counterflow in the hypolimnion. This is the interpretation of the hydrodynamic model. The locally measured temperature profiles can be compared directly to the calculated development of the temperatures (see bottom of Fig. 8).

Due to the strong wind event, a strong shift in the epilimnion water has been observed, with the consequence that at the observation point S2 hypolimnion water is upwelling to the surface. Observation point S2 is located near the sill of Mainau, which separates the main basin from the Überlinger See. The agreement between observation and model calculation is quite good. The internal wave movement before the wind event started as well as the upwelling caused by the wind event are simulated appropriate to the observations. 

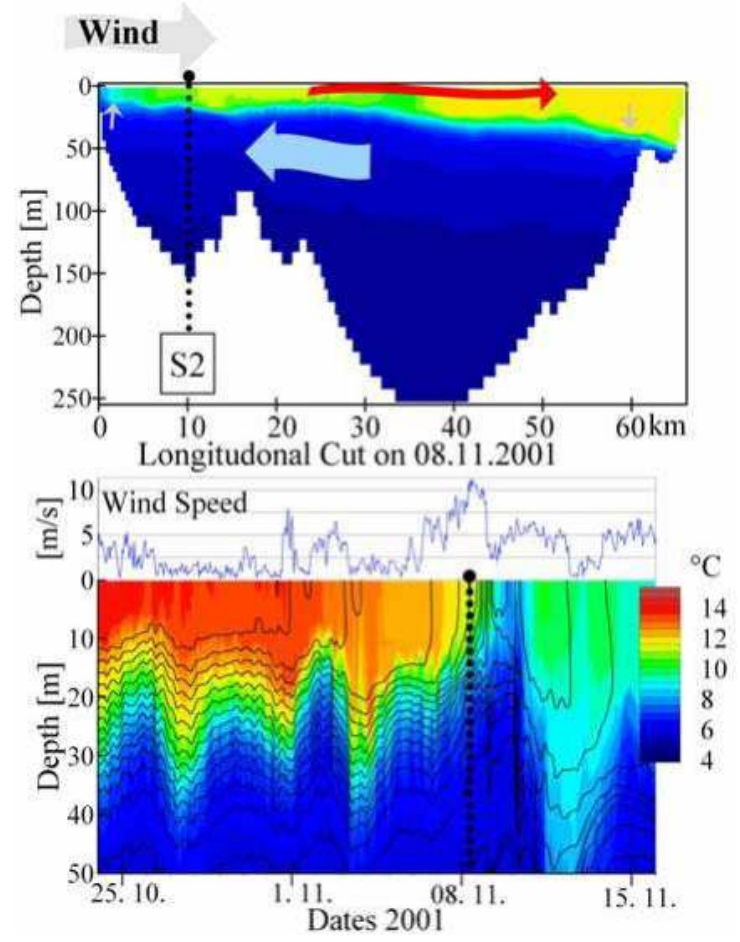

Fig. 8. Upper part: calculated temperature distribution along the longitudinal cut during a strong westerly wind: arrows show flow direction in the epilimnion- and hypolimnion. Lower part: measured (colours) and calculated (lines) temperature profile over time at point S2.

\subsection{Flood event August 2005}

Another set of data for validation of the model system was provided by an extreme flood event in summer 2005. The Alpenrhein entered the lake with a very high load of sediment and fairly warm temperatures. Due to the sediment load, the warm river water produced a downward density current, which reached the deepest part of the lake. The water temperatures at the lake bottom, which normally are around 4 to $5^{\circ} \mathrm{C}$, temporarily reached values of up to $8^{\circ} \mathrm{C}$. After the coarse sediment fractions had settled out, the warm water with the remaining fine sediments produced a buoyant plume rising to the thermocline, from where it was transported with the large-scale lake circulation. It finally reached the water supply intakes on the northern shore where it was observed as a strong increase in turbidity.

Observed values at two waterworks compared to model calculation results, which show fairly good agreement for this extremely complex process, are shown in Fig. 9. The first arrival time of sediment concentration and start of turbidity agrees between the observation and calculation, as well as the time lag between the two observation points because of the travel time between Immenstaad and BWV. While the maximum concentrations of turbidity and solid concentration can not directly be compared but the relation between the two observation points, which is very similar between the calculation and observation. 


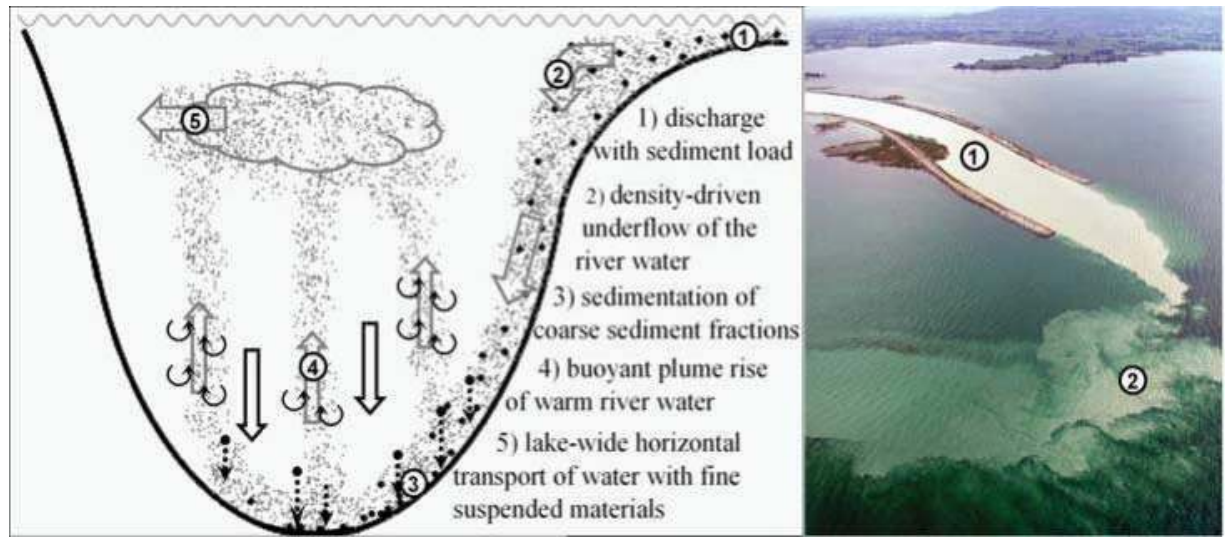

Fig. 9. Inflow of warm water during a flood event and density driven transport mechanism in the lake (photo: Peter Rey, HYDRA)

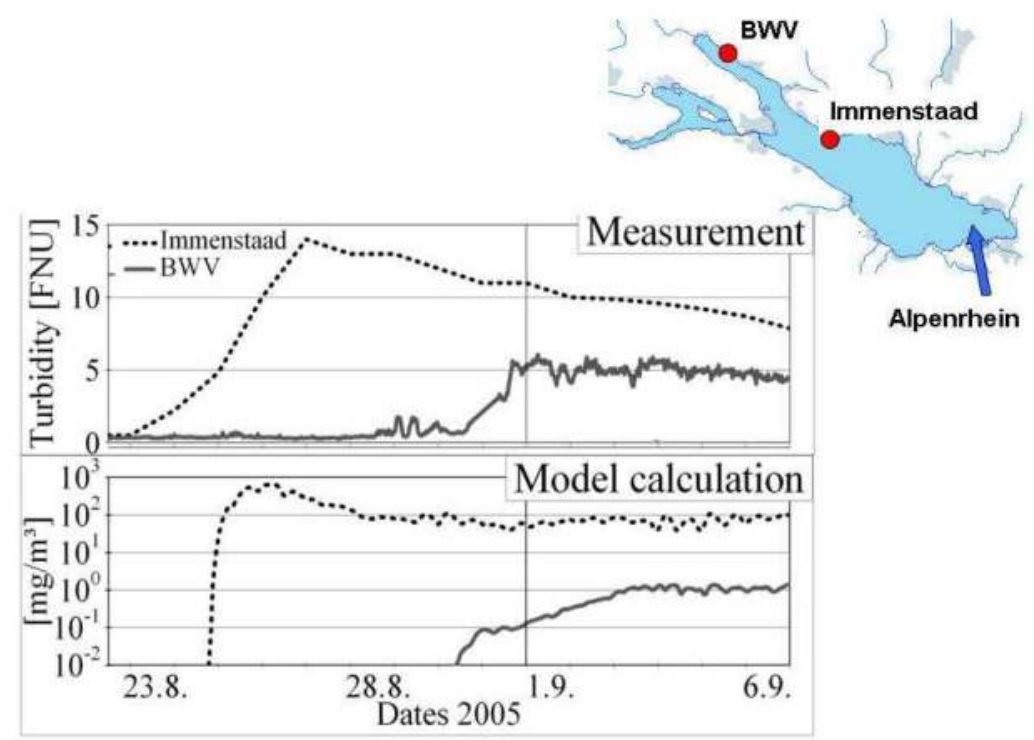

Fig. 10. Calculated suspended solid concentration and observed turbidity at two drinking water supply intakes after the extreme rain event in August 2005 with high discharge of warm water and sediment from the Alpenrhein

\subsection{Field campaign 2007}

During spring 2007, a lakewide field campaign was conducted in order to assess the threedimensional distribution of temperature, phytoplankton, zooplankton, and fish (Eder et al. 2008). These biological parameters were measured in several cross sections at different dates 
to analyse their spatial distribution. The field campaign took place during a period of weak stratification with a strong wind event on the $8^{\text {th }}$ of May 2007, which disturbed the stratification temporarily.

The three-dimensional online ecological-hydrodynamic model was used to simulate the processes during the field campaign. The model started at the beginning of algae growth in early spring. Fig. 11 shows the development of temperatures during the campaign calculated by the model as well as the temperatures observed at Überlinger See. The temporal development of the calculated temperatures agreed very well with the observations (see Fig. 11).

The observed distributions of plankton and temperatures were heavily affected by the strong westerly wind which forced the warm epilimnetic water into the Eastern part of the lake. Whereas, at the same time cold, hypolimnetic water depleted of plankton was upwelling to the surface in the western part.

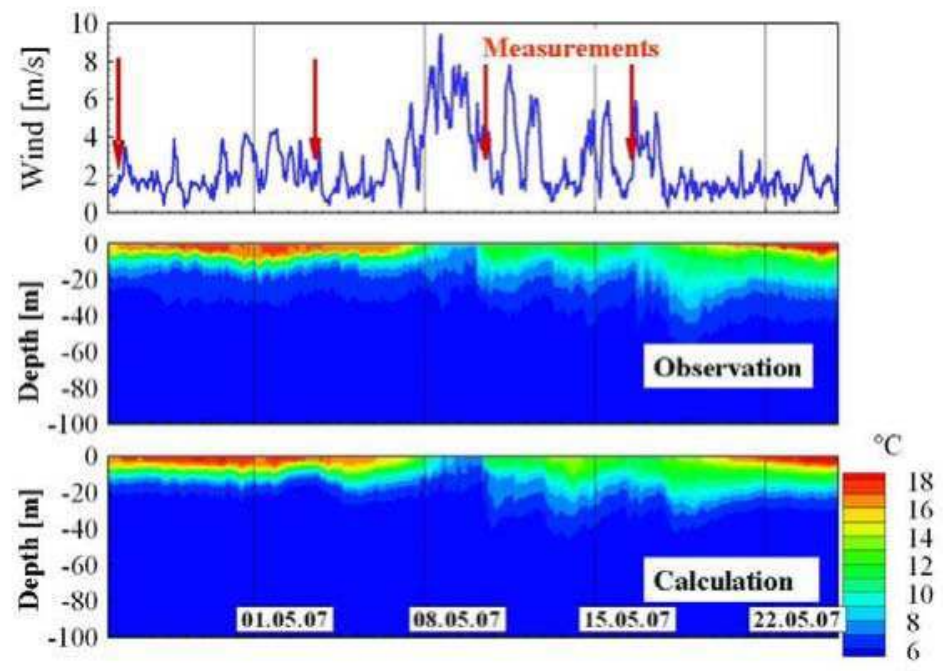

Fig. 11. Observed wind speed, observed and calculated temperature profile in Überlinger See during field campaign 2007

In Fig. 12, the distribution of chlorophyll A concentration in the lake was observed at two dates during the campaign. The comparison with the simulation results shows a good agreement. Direct after the wind event on the $10^{\text {th }}$ of May, the algae had been transported to the Eastern part of the lake and to the Northern and Southern shores. At the second measurement (16th of May) the phytoplankton returns to Überlinger See with the same concentration as in the main basin.

The vertical cross section in Fig. 13 demonstrates that the vertical structure of the phytoplankton distribution is also simulated well in the numerical model. The main concentrations of phytoplankton can be found in this cross section near the Northern and Southern shores. 


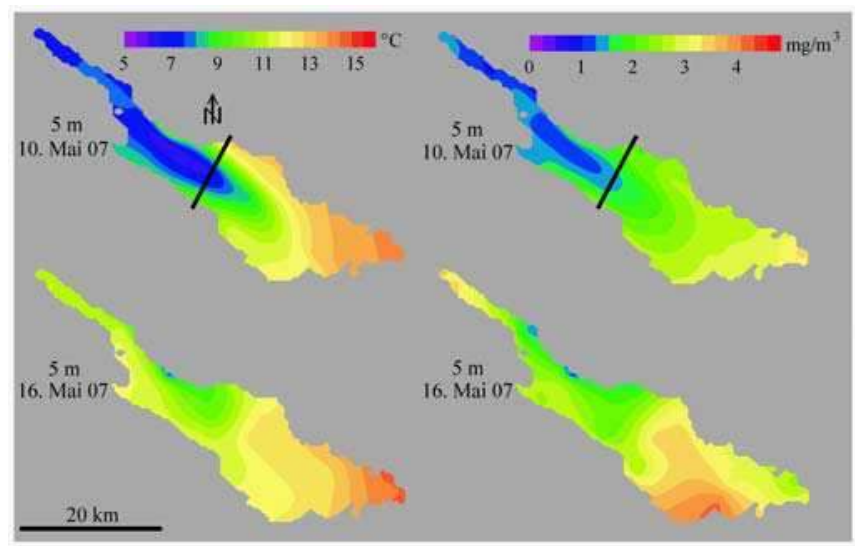

Fig. 12. Measured (left) and calculated (right) concentration of chlorophyll A at $5 \mathrm{~m}$ depth on two different days during field campaign 2007 (the black lines mark the location of the cross section in Fig. 13
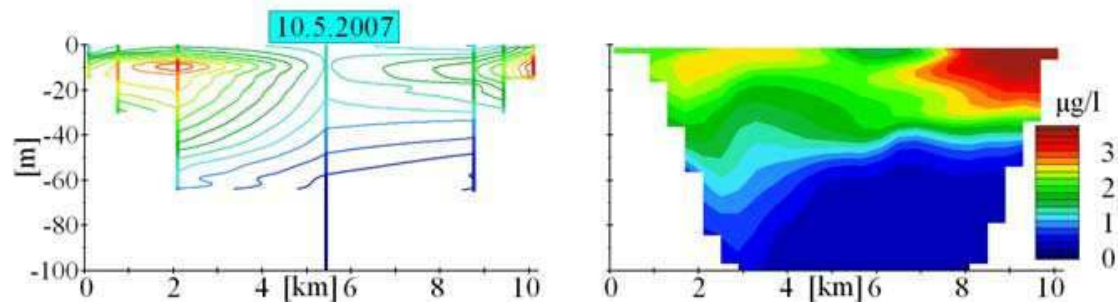

Fig. 13. Measured (left) and calculated (right) concentration of chlorophyll A in a vertical cross section (location see Fig. 12)

\section{User needs and applications}

The decision support system BodenseeOnline is of direct interest primarily for the water authorities of the riparian countries and for the water suppliers. Also, the system provides decision support for the design of protection measures and in cases of accidents. For catastrophic events or accidents, it is also of prime interest for the water police, fire brigades, and communities. Additionally, the databank is of direct interest for research institutions, for industries (cooling water, industrial water needs, energy), for organisations, for the environment, navigation, and tourism, as well as for the general public.

Regarding water resources management, it provides information for decisions with respect to the effects of hydraulic structures or events and activities leading to a change of inflow of substances. It allows prognoses for assessing the effect of measures for maintaining and improving the water quality and provides early warnings about the effects of floods on embankments and settlements.

Furthermore, the model system provides a framework for investigating local issues, based upon more refined local models with dynamic boundary conditions from the large scale 
model system. Examples are local inflow problems for tributaries (e.g. Schussen) or for the discharge of treated sewage water from water treatment plants, morphological changes or discharge of sediments in the lake, effects of changing the shoreline geometry, hydraulic structures, etc.

An important question that will be addressed with the model system relates to the possible effects of climate change on the lake and its ecology. First signals are the observation of several new species in the lake and the fact that during mild winters the lake does not show a complete turnover and mixing of the deep layers with a corresponding reoxygenation of the hypolimnion. Presently, the lake has good water quality and considerable oxygen concentrations in the deep layers, which have been maintained most recently even after two mild winters without turnover. However, if mild winters would occur more often, eventually the hypolimnion will exhibit anaerobic conditions with possibly dramatic effects for the water quality of the lake.

A prototype of the DSS BodenseeOnline for accidents, disturbances, pollution, or extreme events has been developed and validated with observed data. The prototype is running in a test phase, where the suitability of the system for practical uses has been demonstrated in several applications. One example is, an oil alert on the 28 th of March 2009 when a large oil film was observed in the eastern part of the lake. The flow path tool was used to identify possible input locations of contamination (see Fig. 13). It demonstrated that the most likely source of contamination is near the Alpenrhein inflow. The calculated travel times indicated that the accident had happened only one or two days before the oil was detected.

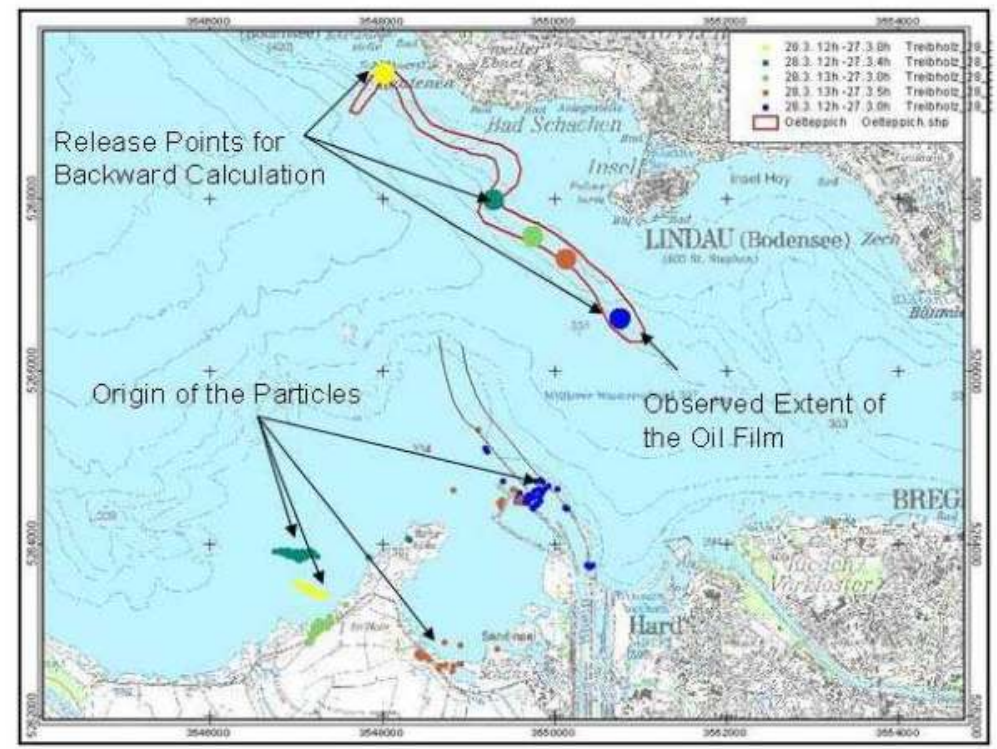

Fig. 14. Application of BodenseeOnline for an observed oil film with backward calculation of particles

Predictions of oil movement showed that the oil slick would be transported in a Southeastern direction in the hours after detection. But a medium wind event destroyed the oil film due to mixing by the surface waves. 


\section{Outlook: Decision support for drinking water treatment plants}

It is planned to develop a further decision support system for the drinking water treatment plant of the main water supplier, Zweckverband Bodensee-Wasserversorgung (BWV). The BWV takes at an average $4 \mathrm{~m}^{3} / \mathrm{s}$ lake water and pumps it to the water work at the hill of Sipplingen. The water is treated in a micro strainer system to remove the large particles. The next treatment step is the input of ozone for water disinfection and sand filters. Several basins are included in the treatment process for intermediate storage or as reactors. The aim of a further decision support system is to simulate the flow and transport through the treatment plant and to have estimations about realistic residence times in case of an accident with hazardous materials.

Fig. 15 shows a first calculation of the flow field in a drinking water basin with a volume of $12065 \mathrm{~m}^{3}$ and a discharge of $2 \mathrm{~m}^{3} / \mathrm{s}$ from left to right. Two tracers are applied to the simulations: tracer 1 entering the basin and tracer 2 being initially placed in the basin water. The outflow concentration of the inflow tracer decreases in several steps in a time period of $25000 \mathrm{~s}$. The mean residence time of the basin is $6032 \mathrm{~s}$. Thus the tracer 2 concentration is at the mean residence time still above $40 \%$, which means that only $60 \%$ of the basin water has renewed after the mean residence time and the total mass of the tracers has exchanged after approximately $25000 \mathrm{~s}$.

The pan is to set up a model for the complete drinking water treatment plant including all relevant substances for the treatment process and having an additional decision support system to control the treatment plant.

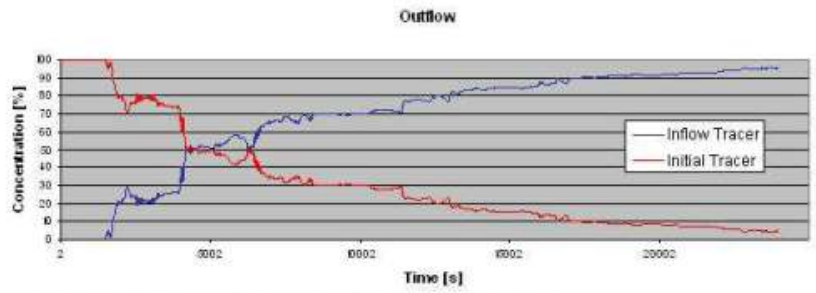

Velocities and Inflow Tracer Concentration after 20 Minutes

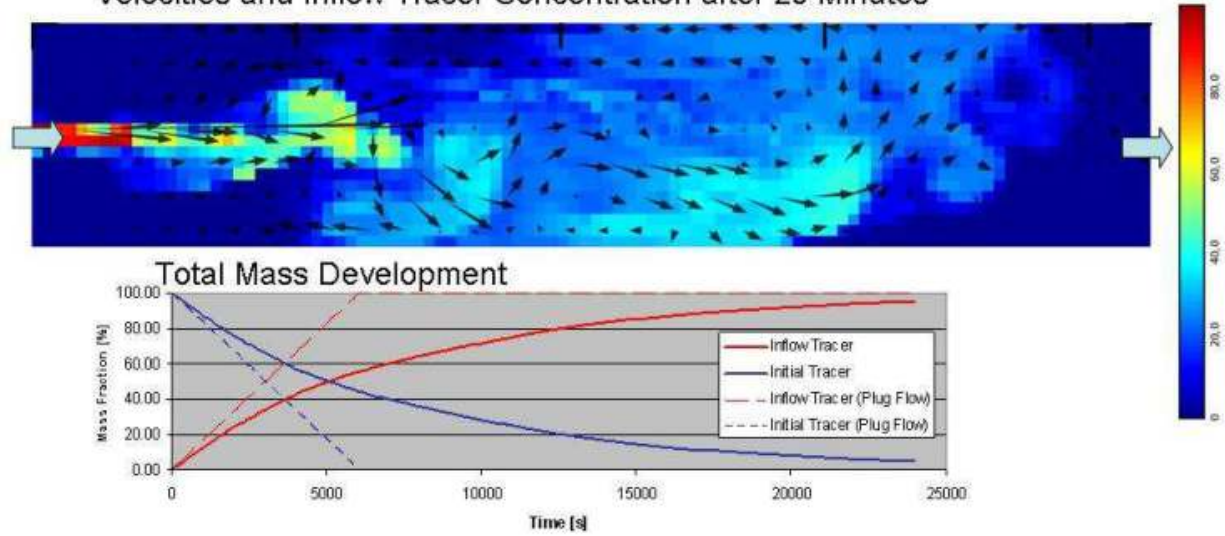

Fig. 15. Calculated tracer concentrations in a drinking water basin, top: Calculated outflow concentrations, middle: distribution of tracer concentration and velocities in a horizontal sheet, bottom: development of the total tracer mass 


\section{Conclusion}

A decision support system for the management of Lake Constance was developed in an interdisciplinary research project over a period of 3 years. In collaboration with the riparian countries Germany, Switzerland and Austria, an online data base has been developed, in which relevant meteorological, hydrological and water quality data of Lake Constance are collected. The data base is coupled with a numerical online modelling system to simulate three dimensional hydrodynamic processes and ecosystem dynamics in the lake. The modelling system consists of a wind model forecasting the two dimensional wind fields over the lake, the hydrodynamic model ELCOM to calculate the flow process in the lake and the ecological model CAEDYM to simulate water quality. The hydrodynamic model is updated daily and a prediction over the next three days is included in the modelling system. The hydrodynamic model is validated on measuring campaigns of major hydrodynamic processes; e.g. wind induced lake wide internal waves during stratified conditions or inflow dynamics under extreme flood conditions with density dependent sediment transport. The water quality model is validated on long term data and lake-wide campaigns on chlorophyll a and zooplankton distributions in Lake Constance in May 2007.

The information system supports water management decisions under water protection aspects and in cases of accidents with hazardous substances. The user has access to the measured and calculated information via internet. Passwords protected areas give an individual view to the data and allow individual analysis of the hydrodynamic system with user initiated calculations for transport of dissolved substances or drifting objects on the lake surface.

The successful development and implementation of the decision support system BodenseeOnline provides a good example that interdisciplinary research is a prerequisite for solving complex water problems. It also shows that interaction among organisations, international cooperation, and data exchange are prerequisites for successful lake management. And finally, it demonstrates convincingly that appropriate hydraulic research can provide a direct approach to integrated and sustainable water management. Research results are implemented directly into daily water resource management.

\section{References}

Appt, J., Stumpp, S. (2002): “Die Bodensee-Messkampagne 2001, IWS/CWR Lake Constance Measurement Program 2001", Mitteilungsheft 111, Institut für Wasserbau, Universität Stuttgart

Appt, J., Imberger, J. und Kobus, H. (2004): Basin-scale motion in stratified Upper Lake Constance. Limnol. Oceanogr., 49: 919-933.

Eder, M., Rinke, K., Kempke, S., Huber, A., Wolf, T.: "Seeweite Bodensee-Messkampagne 2007 als Test für BodenseeOnline“" Wasserwirtschaft 10/2008, pp.34-38

Hamilton, D P. and Schladow, S.G. (1997): "Prediction of water quality in lakes and reservoirs: Part I - Model description", Ecological Modelling

Hipsey, M.R., Romero, J.R., Antenucci, J.P., Hamilton, D. (2007): Computational Aquatic Ecosystem Dynamic Model: CAEDYM, v3 Science Manual. Centre for Water Research (CWR), University of Western Australia, 2007

Hodges,B., Dallimore,C (2006).: Estuary , Lake and Coastal Ocean Model ELCOM, v.2.2 Science Manual. Centre for Water Research (CWR), University of Western Australia 
Holthuijsen, L.H., Booij, N. and T.H.C. Herbers (1989): A prediction model for stationary, short-crested waves in shallow water with ambient currents, Coastal Engineering, 13, 23-54

IGKB (2004): Der Bodensee, Zustand - Fakten - Perspektiven, Internationale Gewässerschutzkommission für den Bodensee (IGKB), 1. Auflage 177 S..

Scheuermann, W., Schmidt, F., Krass, C. (2008): "Modellierung des Windfeldes als Antriebskraft für die interne Strömung im Bodensee“ , 10/2008, pp.22-25 


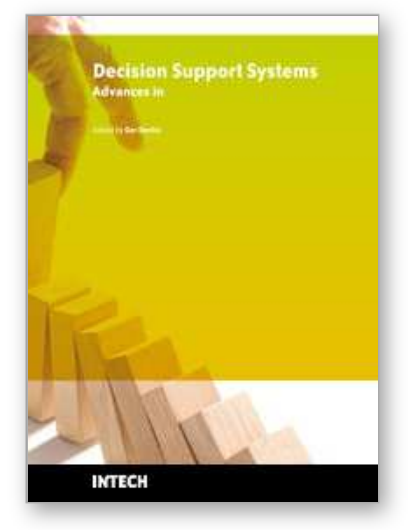

\author{
Decision Support Systems Advances in \\ Edited by Ger Devlin
}

ISBN 978-953-307-069-8

Hard cover, 342 pages

Publisher InTech

Published online 01, March, 2010

Published in print edition March, 2010

This book by In-Tech publishing helps the reader understand the power of informed decision making by covering a broad range of DSS (Decision Support Systems) applications in the fields of medical, environmental, transport and business. The expertise of the chapter writers spans an equally extensive spectrum of researchers from around the globe including universities in Canada, Mexico, Brazil and the United States, to institutes and universities in Italy, Germany, Poland, France, United Kingdom, Romania, Turkey and Ireland to as far east as Malaysia and Singapore and as far north as Finland. Decision Support Systems are not a new technology but they have evolved and developed with the ever demanding necessity to analyse a large number of options for decision makers (DM) for specific situations, where there is an increasing level of uncertainty about the problem at hand and where there is a high impact relative to the correct decisions to be made. DSS's offer decision makers a more stable solution to solving the semi-structured and unstructured problem. This is exactly what the reader will see in this book.

\title{
How to reference
}

In order to correctly reference this scholarly work, feel free to copy and paste the following:

Ulrich Lang, Roland Schick and Gerd Schroder (2010). The Decision Support System BodenseeOnline for Hydrodynamics and Water Quality in Lake Constance, Decision Support Systems Advances in, Ger Devlin (Ed.), ISBN: 978-953-307-069-8, InTech, Available from: http://www.intechopen.com/books/decision-supportsystems-advances-in/the-decision-support-system-bodenseeonline-for-hydrodynamics-and-water-quality-inlake-constance

\section{INTECH}

open science | open minds

\author{
InTech Europe \\ University Campus STeP Ri \\ Slavka Krautzeka 83/A \\ 51000 Rijeka, Croatia \\ Phone: +385 (51) 770447 \\ Fax: +385 (51) 686166 \\ www.intechopen.com
}

\author{
InTech China \\ Unit 405, Office Block, Hotel Equatorial Shanghai \\ No.65, Yan An Road (West), Shanghai, 200040, China \\ 中国上海市延安西路65号上海国际贵都大饭店办公楼405单元 \\ Phone: +86-21-62489820 \\ Fax: +86-21-62489821
}


(C) 2010 The Author(s). Licensee IntechOpen. This chapter is distributed under the terms of the Creative Commons Attribution-NonCommercialShareAlike-3.0 License, which permits use, distribution and reproduction for non-commercial purposes, provided the original is properly cited and derivative works building on this content are distributed under the same license. 